\title{
Presentation of the Howland Award to Helen Brooke Taussig
}

\author{
Robert E. CoOKe ${ }^{[7]}$ \\ Johns Hopkins Hospital, Baltimore, Maryland, USA
}

The primary purpose of the Howland Award is to honor the accomplishments of exceptional contributors to the well-being of children, but an equally important by-product is to identify models of desirable life styles. This is particularly true because pediatrics has the awesome responsibility for advising society on goals for successful parenthood.

The Howland medalists, including the present one, have all exhibited a common characteristic that represents the icleal model for all child rearing-the enjoyment of socially useful achievement. I emphasize enjoyment and I emphasize achievement. There seem to be five necessary elements for success in such a pursuit. First, and possibly the most important, the wise choice of parents. Second, a cultural heritage of scholarship. Third, an inwardly clirected style that comes from adequate self-confidence. Fourth, the opportunity for self-generated or externally imposed challenges. Fifth, appropriately applied direction and encouragement.

Helen Brooke Taussig is a remarkable product of all five elements. She was born on May 24, 1898, to one of the first Radcliffe graduates, but I believe that her father (Fig. 1) was the major influence in her early life.

Frank William Taussig was a world renowned economist who served as Henry Lee Professor of Economics at Harvard University. The cultural influence of scholarship was supplied in part at least by lively discussions in the Taussig home with Abbott Lawrence Lowell, the President of Harvard.

Helen Taussig was athletic as well as intellectual, and was Radcliffe's tennis champion. She transferred to the University of California at Berkeley at the end of her second collegiate year to find new challenges. This was years before the Women's Liberation Move- ment, and she had no jeans and no guitar. But she did have an abundance of freedom of spirit, despite the use of now-discarded foundation garments.

Challenges self-made or externally imposed were the major influence in Helen Taussig's life. When she applied in 1922 at Harvard's new School of Public Health, rather than the Medical School since President Lowell dicl not believe that women belonged in medicine, she was interviewed by Dean Rosenow. He informed her that women could attend classes but they could not obtain a degree.

"Who is going to be such a fool as to spend years studying and not get a degree?" Helen asked.

"No one, I hope." replied the Dean.

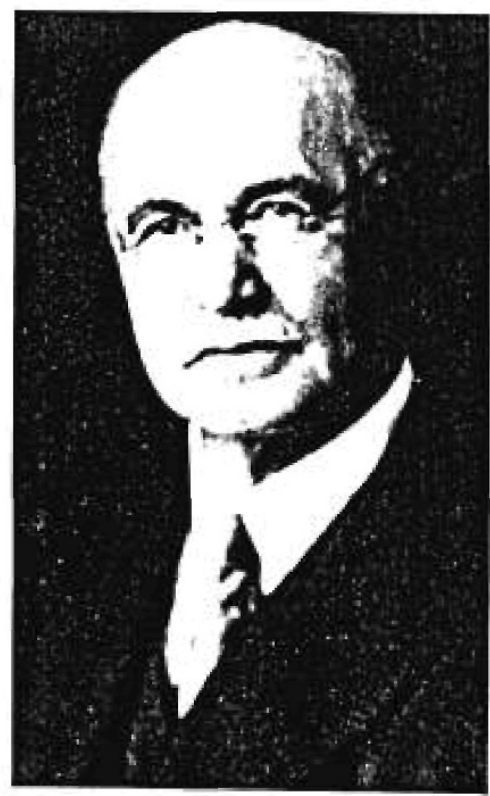

Fig. 1. Frank William Taussig. 
"Doctor Rosenow," she said, "I will not be the first to clisappoint you!"

Then and there she decided to study medicine, and Doctor Alexander Begg, Dean of Boston University, gave her a chance to study anatomy. But almost 50 years before, a wise woman, Mary Elizabeth Garrett (who did wear foundation garments) also gave her a chance to enter medicine by pledging $\$ 500,000$ to the Johns Hopkins School of Medicine to permit it to open, on the condition that the Medical School admit women on the same basis as men. This pledge gave Johns Hopkins one of its most illustrious graduates and faculty members.

On graduation from Hopkins, Doctor Taussig wished to be an internist cardiologist, but she was passed over and she entered pediatrics at the Harriet Lane Home for Invalid Children. I suspect she felt some satisfaction, but no malicious pleasure, when she was made an Honorary Fellow of the American College of Cardiology in 1960 and the first woman President of the American Heart Association in 1965.

At the Harriet Lane Home, Doctor Eclwards A. Park provided her with the necessary direction and encouragement. He pointed out that a pediatric heart clinic must be concerned with congenital heart disease and not just rheumatic fever. Here too was an enormous challenge. Moderately deaf at this time, Doctor Taussig discarded the undue dependence on auscultation, and developed unmatched skills in palpation and especially observation.

$\mathrm{X}$-ray and fluoroscopy became invaluable tools for the new pediatric cardiologist. Extensive detailed records were her habit just as with her colleague, Lawson Wilkins, but she applied her own creativity by introducing into what had been a total anatomical approach the deductive approaches of physiology. By so doing she destroyed the popular mythology of congenital heart disease, that cyanotic lesions were all the same. She showed that pulmonary stenosis of tetralogy of Fallot led to reduced flow to the lungs, and this was the basis of Taussig's and Blalock's corrective procedure.

The challenge was imposed to produce a practical correction of congenital heart disease of the Fallot type. Doctor Robert E. Gross, she learned, was occupied with other surgical problems, but, in 1941, Alfred

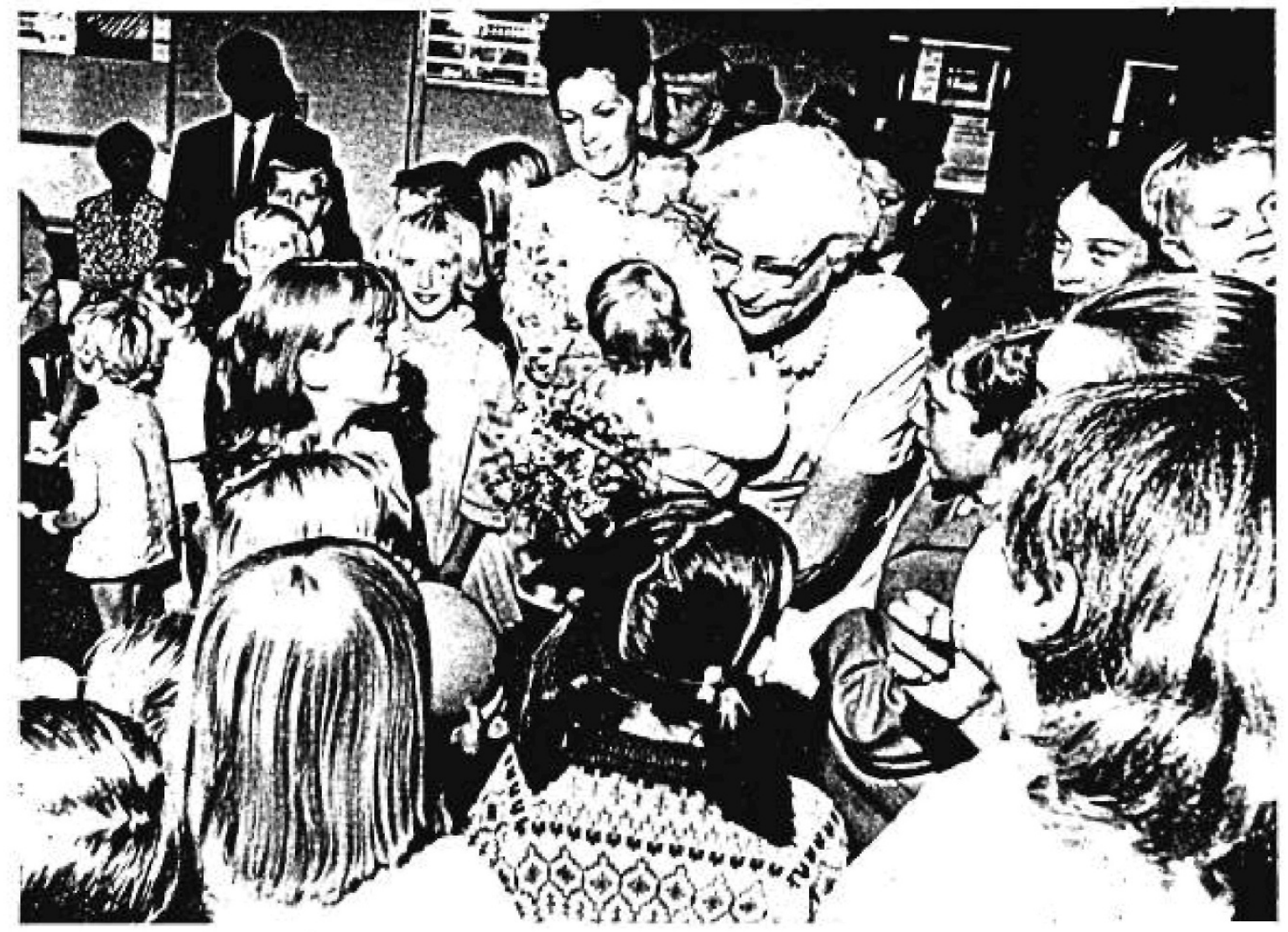

Fig. 2. Dr. Helen Taussig with "friends." 
Blalock came to Hopkins as Professor of Surgery and the years of thought and study came to fruition.

The revolution in approach to congenital defects cannot possibly be appreciated by many of the younger members of these Societies. The diagnosis of "poor protoplasm," the diagnosis of "plain congenital heart disease," the hopelessness, the "send home to die attitude" disappeared in 1945 with the publication in the Journal of The American Medical Association of "The Surgical Treatment of Malformations of the Heart in Which There is Pulmonary Stenosis or Pulmonary Atresia" [2]. I need not recite the resulting honors, the appointments, the honorary degrees, and the awards. This new outlook was rapidly applied to other congenital lesions, and there was a new area for pediatric optimism.

Doctor Taussig's enormous organizational capabilities permitted voluminous publications and yet extraordinary accuracy. In 20 years there were only two minor errors of fact in her text on congenital heart disease. Although she claims a touch of dyslexia, I suspect a greater fondness for creating than being influenced.

This recital might well be interpreted as another example of the Horatio Alger theory-the overcoming of adversity - as described in Garry Wills' recent book, Nixon Agonistes [6]. But in contrast to the title character there has been no personal aggrandizement and no loss of humanity (Fig. 2).

It is probably no coincidence that the first societies among the many in her curriculum vitae are the So- ciety for Pediatric Research and the American Pediatric Society. First and foremost she is a pediatrician. Her concern is with the well-being of children everywhere-the thalidomide victims in Germany, the maimed children in Vietnam.

No challenge is too great for this creative mind. No challenge is too arduous to undertake. As I introduce with great pleasure and pride Doctor Helen Taussig as the recipient of the 1971 John Howland Award, I can only conclude: Thank Godl She came one generation too soon or the first small step on the surface of the moon made for mankind would have been made by a female foot!

\section{References and Notes}

1. Alvakez, W. C.: Our first woman doctor. Mod. Med., 39: 98 (1971).

2. Blalock, A., and Taussig, H. B.: The surgical treatment of malformations of the heart in which there is pulmonary atresia. J. A. M. A., 128: 189 (1945).

3. Clymer, E., and Ertici, L.: Helen B. Taussig: In: Modern American Carcer Woman. (Dodd, Mead and Company, New York, 1959).

4. Froslid, E. K.: Helen Taussig. In: Science Year: The IVorld Book Science Annual. (Field Enterprises Educational Corporation, Chicago, 1967).

5. Ravirch, M.: Summing up. In: The Papers of Alfred Blalock, Vol. 1 (The Johns Hopkins Press, Baltimore, 1966).

6. Win.s, G.: Nixon Agonistes. The Crisis of the Self-Made Man. (Houghton Mifflin Company, Boston, 1970).

7. Requests for reprints should be addressed to: Robert $\mathrm{E}$. Coоke, M.D., Department of Pediatrics, Johns Hopkins I Iospital, Baltimore, Md., 21205 (USA).

8. Accepted for publication June 4, 1971. 